\section{Perfil sócio-demográfico e psicossocial de puérperas adolescentes do Município do Rio de Janeiro, Brasil - 1999-2001}

\author{
A socioeconomic and psychosocial profile \\ of post-partum adolescents in the City \\ of Rio de Janeiro, Brazil, 1999-2001
}

\author{
${ }^{1}$ Departamento de \\ Epidemiologia e Métodos \\ Quantitativos em Saúde, \\ Escola Nacional de Saúde \\ Pública, Fundação Oswaldo \\ Cruz, Rio de Janeiro, Brasil. \\ Correspondência \\ Maria do Carmo Leal \\ Rua Leopoldo Bulhões 1480 , \\ Rio de Janeiro, $R J$ \\ 21041-210, Brasil. \\ duca@ensp.fiocruz.br
}

\begin{abstract}
This study aimed to describe the socioeconomic and psychosocial characteristics of a sample of teenage mothers classified according to marital status and age group. A sample of 1,228 adolescent mothers was interviewed in the immediate post-partum, selected from public and private hospitals in the City of Rio de Janeiro, Brazil. The chi-square test $\left(\chi^{2}\right)$ was used to verify the hypothesis of homogeneity of proportions. Comparing the groups, we found that single and younger adolescents were at increased risk of unwanted pregnancy, less family support, and more abortions. Fathers of the infants also tended to be adolescents and unemployed. Adherence to prenatal care was influenced by the adolescent's marital status. The results showed that the most disadvantaged socioeconomic and psychosocial conditions were found among single and younger adolescents.
\end{abstract}

Pregnancy in Adolescence; Social Conditions; Adolescent

\author{
Adriane Reis Sabroza 1 \\ Maria do Carmo Leal 1 \\ Silvana Granado Nogueira da Gama 1 \\ Janaína Viana da Costa 1
}

\section{Introdução}

O declínio das taxas de fecundidade desde a década de $70{ }^{1}$ parece caminhar contrariamente à crescente incidência de gestação na adolescência 2. Esta é considerada em diversos países como sério problema de saúde pública em virtude do impacto que pode trazer à saúde materno-fetal e ao bem-estar social e econômico de um país 3,4 .

O aumento da fecundidade no grupo etário das adolescentes vem atingindo distintas sociedades. Entre os países desenvolvidos, os Estados Unidos apresentam uma das mais altas taxas de gravidez na adolescência 5,6.

No Brasil, dados do censo de 1991 do Instituto Brasileiro de Geografia e Estatística apontam para uma tendência à diminuição do número de filhos por mulher em idade reprodutiva, que era da ordem de 5,8 em 1970, passou para 4,8 em 1980, para 2,9 em 1991 e 2,3 em 2000 7. Estudo de Gama et al. 8 indica que o Município do Rio de Janeiro, entre 1980 e 1995, acompanhou a tendência ao aumento da gravidez precoce observada no País. Dos cem mil nascidos vivos, 20,0\% eram filhos de mães adolescentes, sendo as taxas de fecundidade mais elevadas no grupo de 15 a 19 anos, com incremento anual de 1,9\%. Dado preocupante é que a faixa de 10 a 14 anos, embora com taxas de fecundidade menores, foi a que apresentou a maior variação positiva, de 7,1\% ao ano. 
A precocidade do início das atividades sexuais, aliada à desinformação quanto ao uso adequado dos contraceptivos e à deficiência de programas de assistência ao adolescente são alguns dos fatores referidos como responsáveis pelo aumento da gravidez, abortamento e doença sexualmente transmissível na adolescência. Também a idade da menarca, que vem se antecipando ao longo dos últimos anos, seria importante contribuinte na precocidade das gestações 9 .

Segundo Cunningham et al. 10, as adolescentes, principalmente as menores de 18 anos, e seus bebês estariam mais expostos a conseqüências negativas quando comparados às mães adultas e seus bebês. Outros trabalhos, entretanto, indicam que as adolescentes no momento da gestação atingem maturidade biológica e endócrina, bem como desempenho obstétrico, como as mulheres adultas 11 . Indicam ainda que a assistência pré-natal adequada exerce impacto positivo sobre o resultado materno e perinatal, chegando eventualmente a anular possíveis desvantagens típicas da idade 12 .

Um outro aspecto relevante refere-se à situação conjugal da gestante. Se em algumas famílias, após a descoberta da gravidez, não há pressão para o casamento, em outras, a única possibilidade de a adolescente ter sua dignidade recuperada é através da união, ainda que esta não corresponda a um desejo do casal. Muitas vezes, a própria gestação é vista pela adolescente como a possibilidade de concretizar o sonho do casamento e alcançar autonomia econômica e emocional em relação à família de origem 13 .

Viver com o pai do bebê, legal ou consensualmente, poderá influenciar o modo como a gestação será percebida e aceita pela adolescente e sua família. De fato, a existência do apoio conjugal traz reflexos na vivência da gestação, assim como na determinação do padrão reprodutivo da adolescente. Estudos demonstram que adolescentes que se casaram durante a gestação eram mais propensas a utilizar métodos contraceptivos após o nascimento do bebê do que as que permaneceram solteiras, sendo estas as mais expostas ao risco de uma gestação subseqüente 14 .

O objetivo deste trabalho foi o de identificar o perfil sócio-demográfico das puérperas adolescentes do Município do Rio de Janeiro, segundo a faixa etária e a situação conjugal. Pretende-se, com base nestes dados, colaborar para a melhoria de políticas de prevenção da gravidez precoce e de atenção pré-natal, tornando-as adequadas a esta população.

\section{Material e método}

O presente estudo foi desenvolvido dentro da linha de investigação sobre " $A$ gravidez na adolescência como variável explicativa do baixo peso ao nascer e outros efeitos adversos no recémnascido em maternidades do Município do Rio de Janeiro", que se constitui um subprojeto do "Estudo da Morbi-mortalidade e da Atenção Peri e Neonatal no Município do Rio de Janeiro". Este, por sua vez, foi feito a partir de uma amostra de 10.072 puérperas que se hospitalizaram em maternidades localizadas no Município por ocasião do parto. As maternidades foram agrupadas em três estratos de tamanhos semelhantes: o primeiro estrato continha estabelecimentos municipais e federais; o segundo, estabelecimentos militares, estaduais, filantrópicos e privados conveniados com o SUS; o terceiro, estabelecimentos privados. Maiores detalhes da amostra estão em Leal et al. 15.

\section{Amostra}

Este artigo analisa os dados de uma subamostra do estudo principal, composta de $1.228 \mathrm{pu}$ érperas com idade entre 12 e 19 anos. Trata-se de um estudo descritivo transversal.

\section{Considerações éticas}

Esta pesquisa foi submetida ao Comitê de Ética de Pesquisa da Escola Nacional de Saúde Pública, Fundação Oswaldo Cruz. O consentimento para a participação no estudo foi dado por escrito pela própria puérpera ou por seu responsável, em caso de menores de idade, mediante um termo de consentimento livre e esclarecido. Nesse documento era explicitado o objetivo do trabalho e informado sobre o direito de optar por participar ou não da entrevista, ou mesmo de desistir durante o decorrer da mesma. Foi também garantido o sigilo quanto à identificação da puérpera.

\section{Desenvolvimento do estudo}

Os dados sócio-demográficos foram coletados diretamente em entrevista com as puérperas de todas as idades por meio de um questionário padronizado aplicado por acadêmicos bol- 
sistas de Enfermagem e Medicina previamente treinados para a função.

No caso de puérperas adolescentes, foi aplicado um segundo questionário, composto com questões acerca de estilo de vida, aspectos emocionais, reação familiar e apoio recebido. Essas entrevistas foram realizadas por uma psicóloga e outras três entrevistadoras da área de saúde, devidamente treinadas pela primeira. Algumas outras informações foram coletadas do estudo principal. Todos os questionários foram submetidos a um processo de revisão e codificação antes de serem digitados.

A amostra de puérperas adolescentes foi analisada segundo o critério da idade materna categorizada por faixas etárias (12 a 16 anos e 17 a 19 anos) e, em um segundo momento, segundo o critério da situação conjugal (com união consensual e sem união consensual). A faixa etária foi definida com base no critério utilizado pela Organização Mundial da Saúde, de 10 a 19 anos 16, todavia, no presente estudo, não obtivemos puérperas com idade entre $10 \mathrm{e}$ 11 anos. A situação conjugal refere-se somente à coabitação, não sendo levada em consideração a duração da união.

A informação sobre a opção pela gestação foi obtida através da questão: "Quando ficou grávida, você: estava querendo engravidar; queria esperar mais um tempo; não queria mais engravidar". Nesse caso, considerou-se como opção pela gestação apenas a primeira resposta.

As informações sobre a reação do pai do bebê à gestação, assim como sobre a reação familiar foram obtidas através de questões semelhantes. Era indagado à puérpera: "Como o pai da criança (sua família) reagiu à notícia da sua gravidez? Opções: bem; de forma regular (mais ou menos); mal; pessimamente; indiferentemente e ele não soube." Em ambos os casos, considerou-se a reação como negativa quando a resposta foi "mal, péssimo ou indiferente".

Todas as variáveis foram analisadas por faixa etária e situação conjugal.

\section{Análise estatística}

Com base nas variáveis consideradas, foram realizadas análises bivariadas. Utilizaram-se testes qui-quadrado $\left(\chi^{2}\right)$ para testar a hipótese de homogeneidade de proporções, em um nível de significância (a) de 5\%, comparando grupos de mães adolescentes a partir de variáveis sócio-demográficas e psicossociais que foram descritas segundo a idade materna e a situação conjugal.

\section{Resultados}

O total de puérperas entrevistadas neste estrato foi de 1.228 , sendo $320(26,0 \%)$ com idade entre 12 e 16 anos, e 908 (74,0\%) entre 17 e 19 anos. A média de idade das puérperas adolescentes foi de 17,3 anos.

Na Tabela 1, são apresentadas estatísticas descritivas relativas a algumas variáveis sóciodemográficas consideradas segundo a faixa etária das puérperas. Em geral, observou-se uma situação mais desfavorável entre as mães mais jovens.

Foi possível observar o predomínio de puérperas de cor parda ou negra na amostra, porém não houve diferenças significativas entre os dois grupos etários, nem em relação ao local de moradia, residência em favelas ou não.

Para as demais variáveis, as diferenças encontradas foram estatisticamente significativas. Entre as mais jovens, foi maior a proporção de adolescentes cuja primeira gravidez ocorreu antes dos 15 anos. Também foi maior neste grupo a proporção de mulheres sem trabalho remunerado, o mesmo ocorrendo com seus companheiros. Quase a metade, 45,9\%, dos pais dos bebês das puérperas mais jovens era também adolescente, enquanto entre mais velhas o percentual foi de 19,9\%. Poucas adolescentes relataram usar algum tipo de método contraceptivo, e entre as mais jovens a ausência dessa prática era ainda mais acentuada, $81,8 \%$, quando comparadas às de mais idade, $74,4 \%$. A maioria das puérperas adolescentes encontrava-se fora da escola ao engravidar, sendo esta proporção mais elevada entre as mais velhas, $60,1 \%$.

Os resultados encontrados demonstram que menos da metade delas considera o estudo como uma possibilidade de ascensão social, e no grupo de 17 a 19 anos esse achado é mais evidente, correspondendo a $38,3 \%$. Por outro lado, a maioria demonstrou interesse em vir a trabalhar no futuro, sobretudo as mais velhas.

Na Tabela 2, são descritos os aspectos psicossociais segundo os mesmos grupos maternos mencionados na tabela anterior. A proporção de puérperas que manifestou não ter desejado a gestação ultrapassou os $60,0 \%$, tendo sido mais elevada entre as mais novas, $69,0 \%$. A reação negativa do pai do bebê e da família foi mais freqüente no grupo de menos idade, respectivamente $18,8 \%$ e $35,0 \%$. O mesmo se observou com a insatisfação materna, bem como com a exposição à agressão física durante a gestação. Diferentemente, a tentativa de aborto e o abandono escolar foram mais freqüentes entre as mais velhas. 
Tabela 1

Proporção de puérperas segundo variáveis sócio-demográficas por faixa etária materna.

Município do Rio de Janeiro, Brasil, 1999-2001.

\begin{tabular}{lcccc}
\hline Variáveis & $\begin{array}{c}\text { Puérpera } \\
12-16 \text { anos } \\
\%\end{array}$ & $\begin{array}{c}\text { Puérpera } \\
17-19 \text { anos } \\
\%\end{array}$ & (1) & (2) \\
& 58,4 & 57,2 & 0,147 & 0,742 \\
\hline Cor da pele parda ou negralor & $\left(\chi^{2}\right)$ & 2,841 & 0,106 \\
Residência em favela/rua & 24,2 & 19,7 & 176,617 & 0,000 \\
1ạ gestação $\leq 14$ anos & 39,4 & 7,7 & 14,552 & 0,000 \\
Mãe sem trabalho remunerado & 94,7 & 86,9 & 31,119 & 0,000 \\
Não vive c/ o pai do bebê & 44,1 & 27,2 & 81,934 & 0,000 \\
Pai do bebê adolescente & 45,9 & 19,9 & 12,612 & 0,001 \\
Pai do bebê desempregado & 30,0 & 20,1 & 7,102 & 0,007 \\
Não usou métodos contraceptivos & 81,8 & 74,4 & 63,607 & 0,000 \\
Não estudava quando engravidou & 34,2 & 60,1 & 6,292 & 0,015 \\
Vê os estudos como possibilidade de ascensão social & 49,7 & 38,3 & 4,811 & 0,033 \\
Não pretende trabalhar & 39,8 & 33,0 & Total: 1.228
\end{tabular}

(1) Teste qui-quadrado $\left(\chi^{2}\right)$ para testar a hipótese de homogeneidade de proporções.

(2) Nível de significância descritivo (p) do teste $\chi^{2}$ de homogeneidade das proporções,

comparando o grupo de 12 a 16 anos com o de 17 a 19 anos.

Tabela 2

Proporção de puérperas segundo variáveis psicossociais por faixa etária materna.

Município do Rio de Janeiro, Brasil, 1999-2001.

\begin{tabular}{|c|c|c|c|c|}
\hline Variáveis & $\begin{array}{c}\text { Puérpera } \\
12-16 \text { anos } \\
\%\end{array}$ & $\begin{array}{c}\text { Puérpera } \\
17-19 \text { anos } \\
\%\end{array}$ & $\begin{array}{l}(1) \\
\left(\chi^{2}\right)\end{array}$ & $\begin{array}{c}\text { (2) } \\
\text { p-valor }\end{array}$ \\
\hline Não desejou a gravidez & 69,1 & 61,4 & 5,968 & 0,015 \\
\hline Reação do pai do bebê negativa & 18,8 & 13,3 & 5,575 & 0,022 \\
\hline Reação familiar negativa & 35,0 & 28,2 & 5,274 & 0,023 \\
\hline Insatisfação com a gestação & 15,6 & 11,1 & 4,446 & 0,038 \\
\hline Tentativa de aborto & 13,0 & 27,2 & 10,194 & 0,001 \\
\hline Fumou na gestação & 7,8 & 11,8 & 3,890 & 0,058 \\
\hline Usou álcool na gestação & 6,9 & 10,3 & 3,151 & 0,093 \\
\hline Usou drogas na gestação & 0,6 & 0,7 & 0,005 & 1,000 \\
\hline Vítima de agressão física durante a gestação & 9,5 & 5,9 & 4,868 & 0,037 \\
\hline 1 a 6 consultas no pré-natal & 52,2 & 55,0 & 0,720 & 0,396 \\
\hline Sentimentos negativos em relação ao bebê & 33,6 & 29,7 & 1,350 & 0,244 \\
\hline Abandonou os estudos & 21,2 & 31,0 & 12,720 & 0,001 \\
\hline Não pretende trabalhar & 39,8 & 33,0 & 4,811 & 0,033 \\
\hline Total da amostra & 320 & 908 & \multicolumn{2}{|c|}{ Total: 1.228} \\
\hline
\end{tabular}

(1) Teste qui-quadrado $\left(\chi^{2}\right)$ para testar a hipótese de homogeneidade de proporções.

(2) Nível de significância descritivo (p) do teste $\chi^{2}$ de homogeneidade das proporções,

comparando o grupo de 12 a 16 anos com o de 17 a 19 anos. 
O consumo de cigarro, álcool e drogas ilícitas foi maior entre as adolescentes mais velhas, mas não estatisticamente significativo. A adesão ao atendimento pré-natal, categorizada pelo número de consultas, bem como os sentimentos apresentados em relação ao bebê por ocasião do parto também não apresentaram diferenças estatisticamente significativas entre os grupos etários.

A Tabela 3 refere-se às mesmas variáveis sócio-demográficas descritas segundo a situação conjugal da adolescente. Foi relativamente alto o percentual de grávidas que afirmaram ter união consensual com o pai da criança $(68,4 \%)$.

As proporções de puérperas segundo a cor da pele, o local de residência e a ausência de trabalho remunerado foram semelhantes quando comparadas pela situação conjugal da mãe. Também não foram estatisticamente significativas as diferenças quanto à perspectiva de ascensão social através do estudo e ao uso de métodos contraceptivos.

Chama a atenção a maior proporção de ocorrência da primeira gestação antes dos 15 anos no grupo de adolescentes sem união consensual. Quanto à idade do pai do bebê e ao fato de ele estar empregado, verificou-se também uma maior proporção de adolescentes e de desempregados no grupo das puérperas sem união consensual. No grupo de adolescentes com união consensual, $61,1 \%$ encontrava-se fora da escola ao engravidar, contra $36,6 \%$ que ainda estudavam. Nesse mesmo grupo, a maioria 38,0\% não tinha a pretensão de trabalhar.

A Tabela 4 descreve algumas características psicossociais segundo o critério de situação conjugal. Desejar a gestação foi menos declarado no grupo de adolescentes que não mantinham uma união consensual com o pai da criança. A reação negativa tanto do pai do bebê quanto da família, a ocorrência de agressão física e a insatisfação da própria puérpera com a gestação atual foram igualmente mais freqüentes nas adolescentes sem união consensual.

As mães sem união consensual apresentaram percentual significativamente maior de abandono escolar nesta gestação, 28,0\%, quando comparadas às demais, $21,7 \%$.

Não se observou diferença na proporção de puérperas que usaram cigarro e drogas ilícitas durante a gravidez em relação à situação conjugal. Já o consumo de bebida alcoólica foi maior entre as que não tinham união consensual, embora não tenha sido estatisticamente significativo.

\section{Discussão}

Mostrou-se adequada a análise de fatores sócio-demográficos e psicossociais, uma vez que eles, principalmente os últimos, são ainda pouco explorados na literatura científica, na qual é muito mais freqüente análise de efeitos biológicos adversos de uma gravidez precoce 17 .

Os resultados obtidos revelaram que as condições sociais de puérperas adolescentes que pertencem ao grupo etário mais precoce e que não possuem união consensual tendem a ser piores.

Observou-se que as adolescentes mais jovens, na maioria das vezes, não apresentam trabalho remunerado, sendo mais dependentes financeiramente, seja da família, seja do companheiro. Paralelamente, a tendência para estabelecer uniões com homens ainda adolescentes, e muitas vezes desempregados, deixa-as em uma situação sócio-econômica mais precária, o que pode torná-las mais expostas a outras situações de risco social.

Sabe-se que, mesmo nos países ricos, engravidar na adolescência reduz as chances de sucesso profissional e que uma gravidez indesejada na adolescência é, muitas vezes, um fator facilitador para a permanência em uma situação de pobreza 18, freqüentemente levando à interrupção do desenvolvimento escolar da adolescente e reduzindo as futuras oportunidades no mercado de trabalho. Os resultados obtidos revelaram que a maioria das adolescentes já se encontrava fora do ambiente escolar, principalmente as de mais idade.

Neste estudo, do total de adolescentes que já haviam abandonado a escola, 26,9\% o fizeram por causa de gestações anteriores (dados não apresentados). Entre as que ainda estudavam no momento em que engravidaram, houve maior abandono escolar nas adolescentes de mais idade e entre as que não tinham união consensual. Um dos possíveis motivos que levariam a adolescente grávida a abandonar a escola seria o receio de ser discriminada, uma vez que evidenciar a existência de uma vida sexual ativa nessa faixa etária ainda é um fato pouco aceito pela sociedade.

Embora os hábitos de fumar, beber ou mesmo usar drogas ilícitas não tenham sido estatisticamente diferentes entre os grupos analisados, acreditamos que a simples presença de tais atitudes mereça atenção quando do planejamento pré-natal da faixa etária em estudo.

Monteiro 19 verificou uma baixa proporção de adolescentes que manifestaram ter desejado a gravidez em curso. Nossos achados são semelhantes, sendo o desejo mais freqüente nos 
Tabela 3

Proporção de puérperas segundo variáveis sócio-demográficas por situação conjugal.

Município do Rio de Janeiro, Brasil, 1999-2001.

\begin{tabular}{lcccc}
\hline Variáveis & $\begin{array}{c}\text { Puérpera } \\
\text { com união } \\
\text { consensual } \\
\%\end{array}$ & $\begin{array}{c}\text { Puérpera } \\
\text { sem união } \\
\text { consensual } \\
\%\end{array}$ & (1) & (2) \\
\hline Idade de 12-16 anos & 21,3 & 36,3 & 31,119 & 0,000 \\
Cor da pele parda ou negra & 55,8 & 61,3 & 3,295 & 0,072 \\
Residência em favela/rua & 21,6 & 19,4 & 0,785 & 0,403 \\
1ạ gestação < 14 anos & 14,3 & 19,6 & 5,613 & 0,019 \\
Mãe sem trabalho remunerado & 89,0 & 88,7 & 0,041 & 0,845 \\
Pai do bebê adolescente & 22,3 & 36,3 & 26,872 & 0,000 \\
Pai do bebê desempregado & 17,3 & 35,3 & 45,760 & 0,000 \\
Não usou métodos contraceptivos & 76,2 & 76,7 & 0,050 & 0,885 \\
Não estudava quando engravidou & 61,1 & 36,6 & 63,318 & 0,000 \\
Não vê os estudos como possibilidade & 59,9 & 53,8 & 1,857 & 0,202 \\
de ascensão social & & & & 12,713 \\
Não pretende trabalhar & 38,0 & 27,6 & 0,000 \\
Total da amostra & 840 & 388 & Total: 1.228
\end{tabular}

(1) Teste qui-quadrado $\left(\chi^{2}\right)$ para testar a hipótese de homogeneidade de proporções.

(2) Nível de significância descritivo (p) do teste $\chi^{2}$ de homogeneidade das proporções,

comparando o grupo de 12 a 16 anos com o de 17 a 19 anos.

Tabela 4

Proporção de puérperas segundo variáveis psicossociais por situação conjugal.

Município do Rio de Janeiro, Brasil, 1999-2001.

\begin{tabular}{lcccc}
\hline Variáveis & $\begin{array}{c}\text { Puérpera } \\
\text { com união } \\
\text { consensual } \\
\%\end{array}$ & $\begin{array}{c}\text { Puérpera } \\
\text { sem união } \\
\text { consensual } \\
\%\end{array}$ & (1) & (2) \\
\hline Não desejou a gravidez & 56,1 & 79,3 & 61,419 & 0,000 \\
Reação do pai do bebê negativa & 9,0 & 27,1 & 68,536 & 0,000 \\
Reação familiar negativa & 25,6 & 39,4 & 24,216 & 0,000 \\
Insatisfação com a gestação & 9,3 & 18,9 & 22,518 & 0,000 \\
Tentativa de aborto & 7,1 & 13,2 & 11,729 & 0,001 \\
Fumou na gestação & 10,6 & 10,9 & 0,018 & 0,921 \\
Usou álcool na gestação & 13,8 & 18,1 & 3,771 & 0,059 \\
Usou drogas na gestação & 0,7 & 0,5 & 0,158 & 1,000 \\
Vítima de agressão física durante a gestação & 5,2 & 10,4 & 11,371 & 0,001 \\
1 a 6 consultas no pré-natal & 55,6 & 51,4 & 1,871 & 0,175 \\
Sentimentos negativos em relação ao bebê & 27,7 & 37,2 & 9,430 & 0,002 \\
Abandonou os estudos & 21,7 & 28,0 & 5,804 & 0,017 \\
Total da amostra & 840 & 388 & Total: 1.228
\end{tabular}

(1) Teste qui-quadrado $\left(\chi^{2}\right)$ para testar a hipótese de homogeneidade de proporções.

(2) Nível de significância descritivo (p) do teste $\chi^{2}$ de homogeneidade das proporções,

comparando o grupo de 12 a 16 anos com o de 17 a 19 anos. 
grupos das mais velhas e com união consensual. O não desejo de engravidar, manifestado pela maioria, revela uma falta de planejamento da reprodução, bastante comum nesse grupo etário, no qual existem dificuldades na utilização de métodos contraceptivos de uso contínuo. Vale ressaltar que o desejo de engravidar também foi pouco freqüente $(46,6 \%)$ entre as puérperas não adolescentes, pertencentes à amostra total do estudo (dados não mostrados). Por outro lado, a constatação de um grupo minoritário, que afirma ter desejado engravidar em uma idade tão precoce, aponta para a imaturidade emocional típica da adolescência, muitas vezes expressa através de comportamentos inconseqüentes, que acabam por se refletir em um modo pouco responsável de exercer a sexualidade.

A precária utilização de métodos contraceptivos pelas adolescentes, mais evidenciada no grupo das mais jovens, é concordante com os dados da literatura. Nos Estados Unidos, apenas uma entre cinco adolescentes que não pretendiam engravidar utilizava algum tipo de método contraceptivo 20.

Como previsto, entre as adolescentes com história de gestação anterior, as mais jovens foram mais propensas a engravidar pela primeira vez antes dos 15 anos, ou seja, em idade muito precoce. Este dado é preocupante, uma vez que o padrão gestacional é geralmente definido na adolescência, de modo que quanto mais jovem for a mãe, maior a probabilidade de multiparidade 1 .

Ainda que a maioria das puérperas, independente da idade, tenha tido acesso aos cuidados pré-natais, observa-se que a aderência às consultas foi influenciada pela presença de uma união consensual, dado relevante na medida em que o pré-natal é apontado na literatura como um dos mais importantes fatores de proteção quanto a efeitos adversos para o bebê 12. A influência dessa união consensual também é apontada por Stern 21, que afirma ser o cônjuge a referência mais importante e que exerce maior influência sobre a adolescente e suas condutas durante a gestação.

A insatisfação com a gestação, neste estudo mais experimentada por adolescentes com menos idade e sem união consensual, provavelmente está relacionada à maior probabilidade de essas adolescentes não terem desejado a gravidez. Estudo de Cowley \& Farley 22 afirma que o fator que melhor prediz a atitude da adolescente em relação à gestação é a percepção de que esta é bem aceita pelo pai do bebê.

As reações negativas à gestação por parte da família e do pai do bebê são mais evidentes entre as mais jovens e sem união consensual. Cabe ressaltar que a aceitação familiar e do companheiro em relação à gravidez pode mostrar-se negativa no início desta, porém tende a melhorar com o passar do tempo, especialmente pela necessidade de apoio das adolescentes.

A constatação de que a experiência da maternidade nos primeiros anos da adolescência influencia negativamente a vivência e os efeitos da gravidez leva-nos a ressaltar a importância do desenvolvimento de políticas públicas que privilegiem a educação sexual como forma de se adiar a ocorrência da gestação. Essas medidas certamente possibilitarão o desenvolvimento de todo o potencial psíquico da adolescente, bem como a ampliação de oportunidades de vida, que venham a garantir uma melhor condição social futura para as gerações subseqüentes.

Chama a atenção o fato de a situação conjugal influenciar no modo como a gestação é percebida pela família e pela própria adolescente, chegando mesmo a alterar padrões relacionais e interferir nos comportamentos ao longo da gestação e, conseqüentemente, afetar o resultado gestacional. Esse achado sinaliza a importância de uma assistência pré e perinatal que inclua não somente a gestante, mas todos os envolvidos, como o companheiro e as famílias de origem de ambos. Tais medidas favoreceriam o estreitamento do vínculo com o pai do bebê e a criação de uma rede social mais efetiva de apoio à adolescente, desfazendo principalmente o mito machista de que a jovem seria a única responsável por essa gravidez inoportuna.

Se ainda não há consenso quanto aos prejuízos biológicos da gravidez nas adolescentes mais jovens, este estudo constata as enormes desvantagens sociais advindas dessa experiência, que não apenas interfere na vida das adolescentes, mas que acaba por repercutir no ambiente conjugal e familiar. 
Resumo

Identificar o perfil sócio-demográfico de puérperas adolescentes, segundo a faixa etária e a situação conjugal. Foram entrevistadas 1.228 adolescentes no pósparto imediato em maternidades públicas, conveniadas com o SUS e privadas do Município do Rio de Janeiro. A análise estatística consistiu em utilizar testes qui-quadrado $\left(\chi^{2}\right)$ para testar hipóteses de homogeneidade de proporções. Ao comparar os dois grupos, observa-se que as adolescentes mais jovens e sem união consensual estão mais sujeitas a engravidar de outros adolescentes, muitos dos quais desempregados; a não desejar a gestação; a não receber apoio familiar ou do pai do bebê e a realizar mais tentativas de aborto. A aderência às consultas pré-natais foi influenciada pela presença de uma união consensual. As adolescentes com menos idade e sem união consensual de monstraram maior insatisfação com a gestação, e a união conjugal influenciou positivamente a maneira como a gestação foi percebida pela família e pela própria adolescente. Os resultados obtidos revelam que as adolescentes em idade mais precoce e sem união consensual apresentam piores condições sócio-demográficas e psicossociais.

Gravidez na Adolescência; Condições Sociais; Adolescente

\section{Colaboradores}

A. R. Sabroza colaborou na coleta e análise de dados, levantamento de referências bibliográficas e redação do artigo. M. C. Leal contribuiu na definição da metodologia, análise e interpretação dos dados e redação do artigo. S. G. N. Gama participou da construção do questionário, na definição das variáveis, análise e discussão dos resultados. J. V. Costa contribuiu na codificação e revisão dos questionários, revisão bibliográfica e na descrição dos resultados obtidos.

\section{Referências}

1. Sociedade Civil de Bem-Estar Familiar no Brasil. Brasil: Pesquisa Nacional sobre Demografia e Saúde. Rio de Janeiro: Sociedade Civil de Bem-Estar Familiar no Brasil; 1997.

2. Camarano AC. Fecundidade e anticoncepção da população jovem. In: Comissão Nacional de População e Desenvolvimento, organizador. Jovens acontecendo na trilha das políticas públicas. Brasília: Comissão Nacional de População e Desenvolvimento; 1998. p. 109-33.

3. Koniak-Griffin D, Anderson NL, Verzemnieks I, Brecht ML. A public health nursing early intervention program for adolescent mothers: outcomes from pregnancy through 6 weeks postpartum. Nurs Res 2000; 49:130-8.

4. Orvos H, Nyirati I, Hajdu J, Pal A, Nyari T, Kowacs L. Is adolescent pregnancy associated with adverse perinatal outcome? J Perinat Med 1999; 27: 199-203.

5. Alan Guttmacher Institute Sex and America's teenagers. New York: Alan Guttmacher Institute; 1994. 
6. Bacon JL. Adolescent sexuality and pregnancy. Curr Opin Obstet Gynecol 2000; 12:345-7.

7. Fundação Instituto Brasileiro de Geografia e Estatística. Censo Demográfico, 2001. Rio de Janeiro: Fundação Instituto Brasileiro de Geografia e Estatística; 2002.

8. Gama SGN, Szwarcwald CL, Leal MD, Theme Filha MM. Gravidez na adolescência como fator de risco para o baixo peso ao nascer no Município do Rio de Janeiro. Rev Saúde Pública 2001; 35:74-80.

9. Treffers PE, Olukoya AA, Ferguson BJ, Liljestrand J. Care for adolescent pregnancy and childbirth. Int J Gynaecol Obstet 2001; 75:111-21.

10. Cunningham FG. Williams Obstetrics. 19th Ed. New Jersey: Prentice Hall International Inc.; 1993.

11. Mathias L, Nestarez JE, Kanas M, Neme B. Gravidez na adolescência. IV - Idade limite de risco reprodutivo entre adolescentes. J Bras Ginecol 1985; 95:141-3.

12. Gama SGN, Szwarcwald CL, Leal MC. Experiência de gravidez na adolescência, fatores associados e resultados perinatais entre puérperas de baixa renda. Cad Saúde Pública 2002; 18:153-61.

13. Desser AD. Adolescência, sexualidade e culpa. Rio de Janeiro: Editora Rosa dos Tempos; 1993.

14. Ford K. Second pregnancies among teenage mothers. Family Plann Perspect 1983; 15:268-72.

15. Leal MC, Gama SGN, Campos MR, Cavalini LT, Garbayo LS, Brasil CLP, et al. Fatores associados à morbi-mortalidade perinatal em uma amostra de maternidades públicas e privadas no Município do Rio de Janeiro, 1999-2001. Cad Saúde Pública 2004; 20 Suppl 1:S20-33.
16. Oraganização Mundical de Saúde. Necessidades de salud de los adolescentes. Informe de on Comitê de Exfrestos de la OMS. Genebra: Organização Mundial de Saúde; 1997. (Serie de Informes Técnicos 609).

17. Weiss AE, Zimmermann CR, Dias D, Myskovski M, Moro R, Silva SQ, et al. Gestação na adolescência. Revista Médica HEC/FEMPAR 1988; 3:1823.

18. Population Reference Bureau. La actividad sexual y la maternidad entre Adolescentes en América Latina y el Caribe: riesgos y consecuencias. Washington, DC: Population Reference Bureau, Demographic and Health Surveys; 1992.

19. Monteiro DLM. Pré-natal na gestante adolescente. In: Monteiro DLM, Cunha AA, Bastos AC, organizadores. Gravidez na adolescência. Rio de Janeiro: Editora Revinter; 1988. p. 57-74.

20. Jones EF, Forrest JD, Goldman N, Henshaw SK, Lincoln R, Rosoff JI, et al. Teenage pregnancy in developed countries: determinants and policy implications. Fam Plann Perspect 1985; 17:53-63.

21. Stern C. El embarazo en la adolescencia como problema público: una visón crítica. Salud Publica Mex 1997; 39:137-43.

22. Cowley C, Farley T. Adolescent girls' attitudes toward pregnancy: the importance of asking what the boyfriend wants. J Fam Pract 2001; 50:603-7.

Recebido em 02/Out/2002

Versão final reapresentada em 23/Jun/2003

Aprovado em 10/Nov/2003 